Bangladesh J. Zool. 42(1): 77-84, 2014

\title{
BLOOD TRANSFUSION TRANSMITTED INFECTIOUS DISEASES (HIV, HBV, HCV, SYPHILIS AND MALARIA) AMONG THE VOLUNTARY BLOOD DONORS IN DHAKA, BANGLADESH
}

\author{
Hamida Khanum, Mafruha Khanom, Hashina Banu, Farhana Muznebin ${ }^{1}$, \\ Shahela Alam and A.Z.M. Shafiullah² \\ Department of Zoology, University of Dhaka, Dhaka-1000, Bangladesh
}

\begin{abstract}
Prevalence of five important blood transfusion-transmitted infectious diseases (HIV, HBV, HCV, Syphilis, and Malaria) were studied among the voluntary blood donors in Dhaka. Out of 1500 donors, positive infections was identified in 99 of cases and rest of the donors were screened negative. Male voluntary blood donor were $82 \%$ and only $18 \%$ were female. About $53.53 \%$ male infectious blood donor had HBV infection whereas, $26.26 \%$ female had HBV. The difference was significant $(\mathrm{P}<0.05)$. In age group of $18-24$ years, $36 \%$ of the donor had HBV infection and HCV was found positive in $04.04 \%$ of student. Among the students, HBV was positive in $44 \%$. Only $01.01 \%$ of teacher was HIV positive. Malaria infection was positive only among the business man (01.01\%). The positive cases $(01.01 \%)$ with TPHA found among the students, teacher and worker and the difference was significant $(\mathrm{P}<0.05) .40 .40 \%$ of the volunteer blood donors were illiterate and $24.24 \%$ donor had Master degree and $8 \%$ HSC passed.
\end{abstract}

Key words: Transfusion transmitted diseases, HIV, HVC, HBV, Syphilis, Malaria

\section{INTRODUTION}

Blood is a special form of natural fluid that is made and synthesized within the body and again used by the body for different bodily function. Despite all the medical advances, there is still no good man-made substitute for human blood, which is why blood donations are still clinically important for the human being (WHO 2004). Blood transfusion is the process of transferring blood or blood based products from donor into the circulatory system of recipient. Blood transfusion is a unique technology in that its collection, processing and use are scientifically based, but its availability depends on the extraordinary generosity of people who donate it. Obviously this donation procedure is completely through the way of blood transfusion. There is a challenge for safe transfusion requires the application of science and technology to blood processing and testing (Shirin et al. 2000, Ahmed 2005).

Every year, millions of people are exposed to avoidable, life-threatening risks through the transfusion of unsafe blood (WHO 2004). There is potential for a number of diseases to be transmitted by transfusion of blood or its components

${ }^{1}$ Department of Zoology, Jagannath University, Dhaka, Bangladesh. ${ }^{2}$ Department of Statistics, Biostatistics and Informatics, University of Dhaka, Dhaka-1000, Bangladesh. 
(Khan et al. 1992, Kothari et al. 2002). For the identification of TTIs, it is necessary to screen blood. A number of infectious (such as HIV, syphilis, hepatitis $\mathrm{B}$ and hepatitis $\mathrm{C}$, among others) can be passed from the donor to recipient (O'Shaughnessy 2000). In Bangladesh, a law has been established to screen blood for HIV, HBV, HCV, syphilis and malaria in case of every blood transfusion (Shill and Biswas 2006, Popovsky et al. 1995, Ayolabi et al. 2006, Chuan et al. 1999, Olamendi et al 1998). The mode of transmission of HBV are intravenous, intramuscular or subcutaneous inoculation or transmission of human blood, plasma, serum, thrombin, red cells and other blood products from an infected persons. The infectious agent is virus of probable DNA nucleic acid content capable of expressing several non-infective morphological forms in addition to an infectious virion (Benenson 1975).

The infectious agent for syphillis is a spirochaete Treponema pallidum. The mode of transmission are by direct contact in heterosexual or homosexual activity with exudates from skin, mucous membrane, secretions and discharges (Benenson 1975). Transmission also occurs through blood transfusion. The reservoir of syphilis is man.

According to WHO blood transfusion strategy (WHO 2004); safe blood transfusion could be achieved by a well-organized, nationally coordinated blood transfusion system (Syed 1996, Chiavetta et al. 2000). The risk of transmission of hepatitis C is said to be 1 in 121,000; hepatitis B, 1 in 66,000 (O'Shaughnessy 2000, Kleinman 2001, Zhang et al. 2001).

The aim of the study was to investigate the prevalence of transfusion transmitted infectious diseases (HIV, HBV, HCV, syphilis and malaria) among the voluntary blood donors. The present study may help in the way to establish a good national strategy for the blood donation system. At least it can give an idea about the current situation of transfusion transmission related infection.

\section{MATERIAL AND METHODS}

The present study was a cross section, descriptive and analytical study. The study place was selected based on available information from the voluntary blood donors attending "The Quantum Foundation" located at Shantinagar, Dhaka-1217. The study was conducted from May, 2011 to April 2012. One thousand and five blood donors were randomly selected for the study. Data were collected based on the protested structured interview schedule. Blood was collected by venipuncture technique (Aseptic and antiseptic presenter) by disposable syringe. Rapid test was used for all the infectious diseases.

Test for HBV: The HBsAg one-step hepatitis B surface Antigen test strip used as a rapid chromatographic immunoassay for the qualitative detection of 
hepatitis B surface antigen in serum/plasma. The membrane was pre-coated with anti-HBsAg antibodies on the test line region of the strip. During testing, the serum or plasma specimen react with the particle coated with HBsAg antibody. The mixture migrates upward on the membrane chromatographically by capillary action to react with anti-HBs antibodies on the membrane and generated a colored line in the test region indicated positive results (Shill and Biswas 2006).

Rapid test for HCV: The rapid Anti-HCV Test is a simple, visual qualitative test that detect antibodies in human whole blood serum/plasma. The test is based on immune-chromatography. The HCV antigen-colloidiluents gold conjugate embedded in the sample pad reacts with the anti-HCV antibody present in whole blood serum and forming conjugate/HCV antibody complex. As the mixture was allowed to migrate along the test strip, the conjugate/HCV antibody complex was captured by an antibody landing protein. An immobilized colored test band in the test region indicated the positive sample for $\mathrm{HCV}$ infection (Shill and Biswas 2006).

Rapid Test for HIV: The general method of detecting infection with HIV is to assay the presence of antibodies to the virus by an EIA method followed by confirmation with Western Blot or PCR. The advanced quality Rapid Anti-HIV Test is a simple visual qualitative test that detected antibodies in human whole blood/serum. The test was done on the basis of immune-chromatography ((Shill and Biswas 2006).

Test for syphilis: The serological tests were most effective diagnostic method in syphilis and two types of antigens were in use; a) Nontreponemal antigen for non-specific regain antibody, and b) Treponemal antigen for specific antitreponemal antibody (Shill and Biswas 2006). In Standard Test for Syphilis (STS), regain antibodies in serum was detected by cardio-lipin antigen were added. Cardio-lipin reacted with the non-specific regain (a mixture of IgM and IgA). Two most widely used STS and Veneral Disease Research/Reference Laboratory Test (VDRL) and Rapid Plasma Reasin test (RPR) were performed (Shill and Biswas 2006).

Treponemal antigen test: Treponema pallidum Hemagglutination Assay (TPHA) is a specific hemagglutination test for diagnosis of syphilis. During screening of syphilis, RPR test was performed for detection of primary and secondary syphilis (microscopically).

Test for Malaria Approximately $5 \mathrm{ml}$ of blood was taken through venipuncture from the donors. Thick and thin smear slides were prepared in duplicate using two drops of blood for each sample. Microscopy: The microscopy results were cross checked by two independent, experienced microscopists. 


\section{RESULTS AND DISCUSSION}

In the present study, about 53.53\% male blood donor had HBV infection whereas, $26.26 \%$ female blood donor had HBV. The difference was significant (P $<0.05$ ). In age group of $18-24$ years about $36 \%$ of the infectious blood donor had HBV infection, $16 \%$ in age range of 25-30 years (Table 1). Age group of 31-36 years had $13.13 \% \mathrm{HBV}, 01.01 \% \mathrm{HCV}, 02.02 \%$ TPHA and $01.01 \% \mathrm{MP}$.

Among the age group 37-42, found positive for HIV (01.01\%), HBV (12.12\%), HCV $(02.02 \%)$, TPHA (01.01\%). Among the age group of 43-48 years, HBV $(02.02 \%)$, TPHA $(01.01 \%)$ found positive. The difference was significant $(\mathrm{P}<0.05)$ (Table 1).

The result of the present study showed that $36.9 \%$ had the age below 25 years and $30 \%$ of the blood donor had the age between 25 to 30 years. The percentage of blood donor decreases exponentially among the people of higher age group. About $36 \%$ of the infectious blood donor had HBV infection that was in age group of $18-24$ years, $16 \%$ of in age range of $25-30$ years, $31-36$ years had $13.13 \%$ HBV. The difference was significant $(p<0.05)$.

Among the students, HBV was positive in 44\%, 16\% in service man, $12.12 \%$ in business man, $03.03 \%$ in teacher and $01.01 \%$ in worker and house wife. Only $01.01 \%$ of teacher was HIV positive, $\mathrm{HCV}$ was found positive in $04.04 \%$ of student, $03.03 \%$ of service and business man and $01.01 \%$ among the workers. Malaria infection was positive $(01.01 \%)$ only among the business man. The positive cases with TPHA found in $01.01 \%$ of student, teacher and worker, $03.03 \%$ of service man and $02.02 \%$ of business man (Table 1). The difference was significant $(\mathrm{P}<0.05)$.

About half of the volunteer blood donors were illiterate $(40.40 \%)$ and $24.24 \%$ had Master degree, $8 \%$ was of HSC group and $7 \%$ had Bachelor level of education (Table 1). The present study observed that about $28 \%$ donor was vaccinated and had the history of HBV infection and half of the infectious donors were infected with HBV. The difference in the percentage of vaccination in volunteer donor with infectious disease was statistically significant $(\mathrm{P}<0.05)$.

Among the respondents with infectious diseases in respect to knowledge about infectious diseases such as HBV, HCV, TPHA and MP were found in 38\%, 03\%, $05 \%$ and $01 \%$ to subjects with the knowledge of severity of the diseases respectively (Table 2 ). 


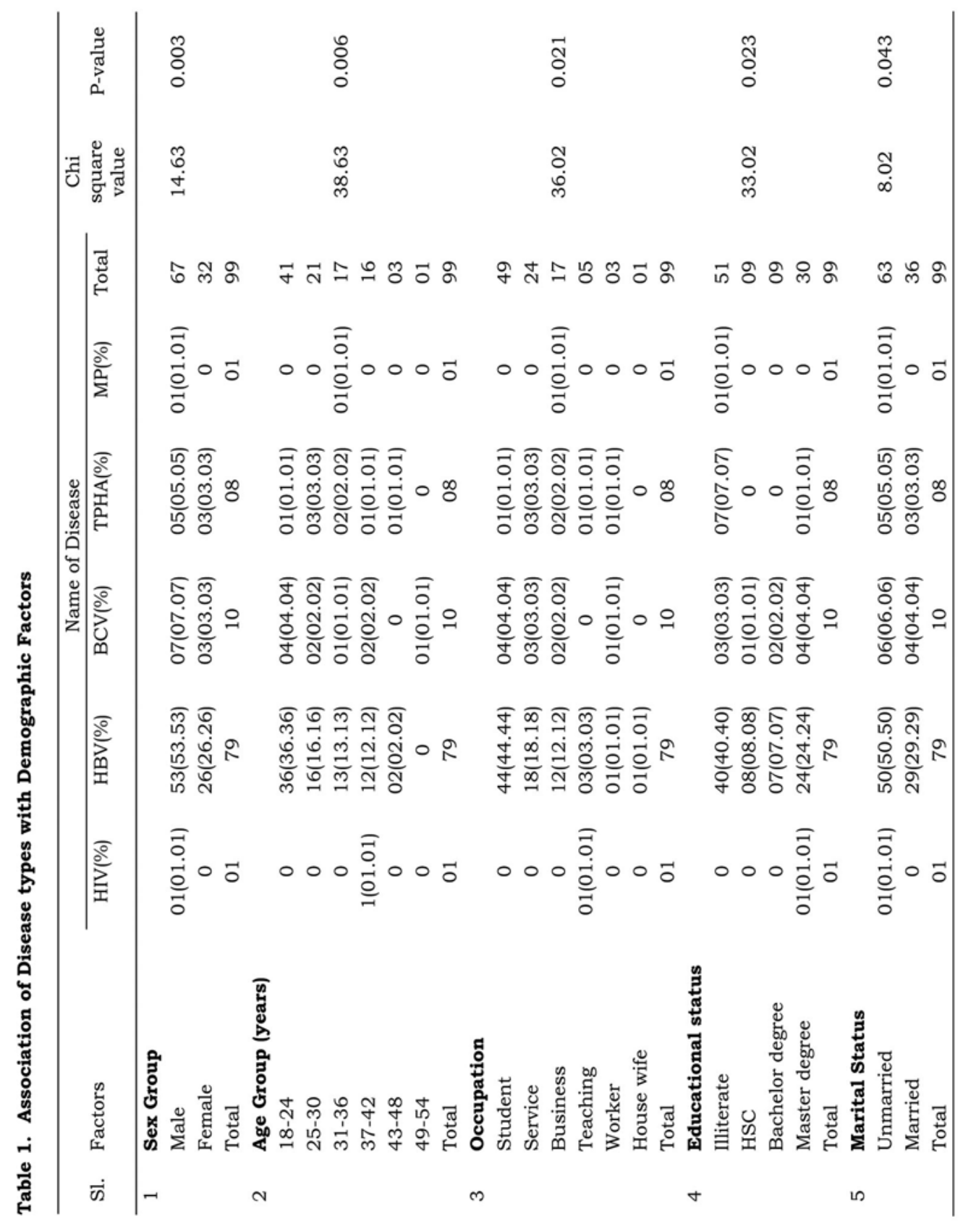




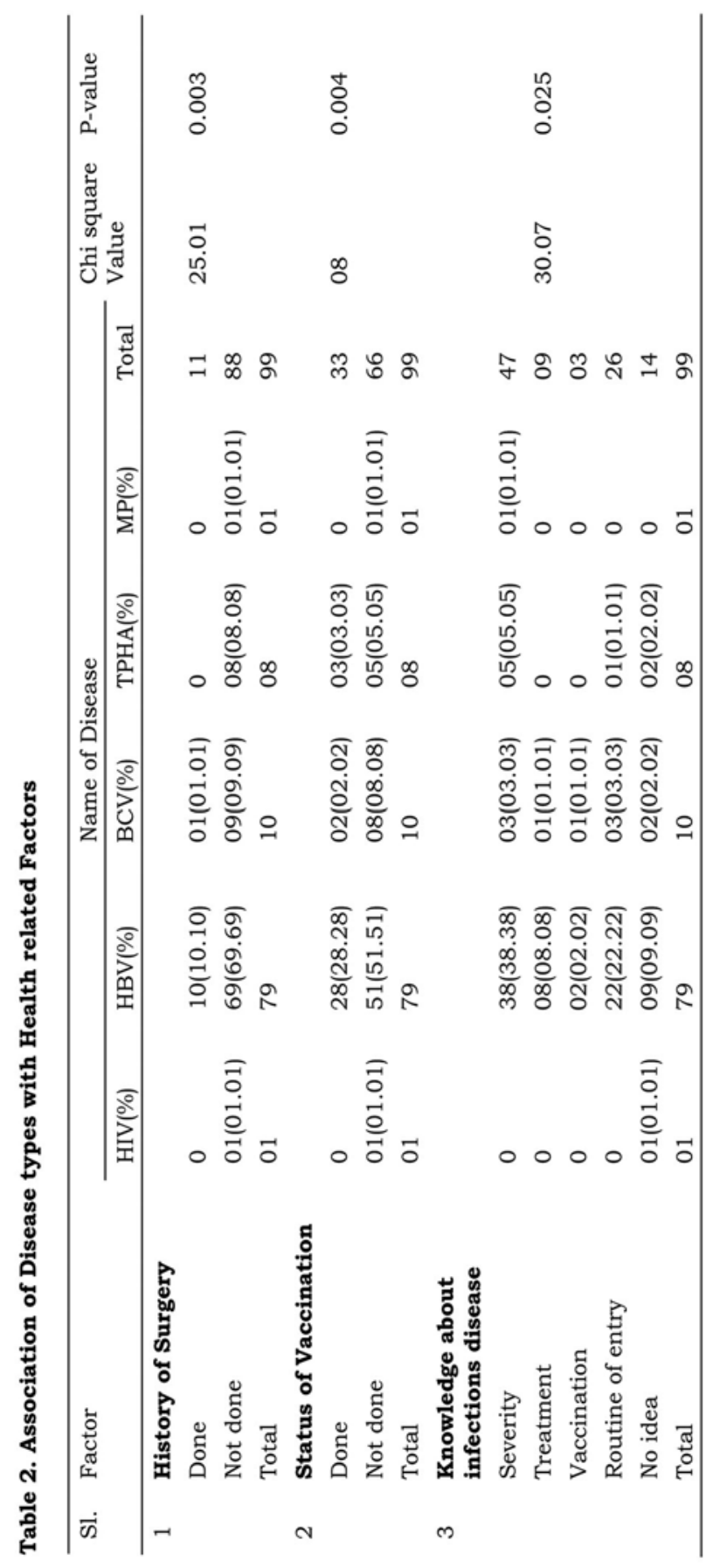


Almost half of the volunteer blood donor (50.55\%) with infectious disease were unmarried while, nearly one third of the donors were married $(29.29 \%)$. The unmarried people were frequent blood donor than that of married counterpart. This was also statistically significant $(\mathrm{P}<0.05)$. (Table 1$)$

Jalali et al. (2007) carried out a study for significant reduce in hepatitis B prevalence among blood donors due to educational and vaccination programmers. They found $0.8 \%(324 / 39,022)$ of blood donors were HBs-Ag reactive. The HBV prevalence was higher in over 49 year's groups, farmer, illiterate and married. On the contrary of the above study, in the present study it was found that, among the voluntary blood donor majority $(78.8 \%)$ had hepatitis $\mathrm{B}$ virus infection. The next common infection was hepatitis $\mathrm{C}$ virus infection $(10 \%)$. The third cause of infection was Syphilis $(8 \%)$. About $1 \%$ donor had malaria and HIV in each group.

Adjei et al. (2003) carried out a study on the prevalence of Syphilis among blood donors in Accra, Ghana and the prevalence rate was $7.5 \%$. In both sexes, the age distribution of subjects positive for Syphilis was from 19-54 (median age, 32) years. Simone et al. (2000) found that, the prevalence of HIV decreased in first time donors from $0.030 \%$ to $0.015 \%(\mathrm{P}=0.006)$ and $\mathrm{HCV}$ from $0.63 \%$ to $0.40 \%(\mathrm{P}<0.001)$. Trends were not statistically significant for the proportion of first time donors with hepatitis B surface antigen (HBsAg).

The present study found that most of the blood donors were students (42.4\%) and within the age-group 18-24 years. Some people donated blood even for 15 times. Blood donation organizations should take precautions and measure to reduce the life threatening infections through transfusion. Awareness and knowledge would be the key to prevent the transfusion of transmissible diseases. Timely vaccination program is also important to prevent the infectious diseases like HIV, HBV, HCV, Syphilis, Malaria, etc.

\section{LITERATURE CITED}

ADJEI, A.A., KUDZI, W., ARMAH, H., ADIKU, T. and ANSAH, J. 2003. Prevalence of antibodies to syphilis among blood donors in Accra, Ghana.Jpn.J. Inect. Dis. 56: 165-167.

AHMED, U.M. 2005. Prevalence of HBsAg in voluntary blood donor. Journal of Teachers Association,Bangladesh. 21(40): 857- 865.

AYOlABI, C.I, TAIWO, M.A., OMILABU, S.A., ABEBISI, A.O. and FATOBA, O.M. 2006.Sero prevalence of hepatitis-C virus among blood donors in Lagos, Nigeria. African journal of Biotechnology. 5(20): 1944-1946.

BENENSON, A.S. 1075. Control of Communicable Diseases in man. Twelfth Edition. The American Public health Association, Washington, DC 20036. pp 413. 
CHUAN, H., FUMiO, N., NOBUYASU, Y., SAKAE, I., MAKI, Y.O., RYO, S. and TOSHIAKI, N. 1999. Transfusion-transmitted virus infection in China: Prevalence in blood donors and in patients with liver diseases. Journal of Gastroenterology and Hepatology. 14(9): 899-903.

CHIAVETTA, J.A, MAKI, E, GULA, C.A. and NEWMAN, A. 2000. Estimated risk of transfusion transmitted infection in the Canadian blood supply (1987-1996). Vox Sang. 78(1): 360.

JALALI, F.M., TORABI, Z.M.J., SAJADI, S.M., PARIDAR, M. and NASIMIAN, A. 2007.Significant reduce in hepatitis $B$ prevalence among blood donors admitted to an AHWAZ blood transfusion service due to educational and vaccination programmes. European Society of Clinical Microbiology and Infectious Diseases, Munich, Germany, 17:34-36.

KHAN, B.K., BISWAS, G.M., HUSSAIN, M.K. and NONDI, C.K. 1992. Prevalence of syphilis and hepatitis-B among the blood donors(professionals and non-professionals, voluntary donors) in different hospitals of Bangladesh. Journal of Medicine Today. 4:52-54.

KLEINMAN, S.H.G.V. 2001. Implications for blood safety policies in Canada. Canada Communicable Diseases Report. (suppl.): 16-19.

KOTHARI, A., RAMACHANDRAN, U.G., GUPTA, P., SINGH, B. and TALWAR, V. 2002. Seroprevalence of cytomegalovirus amongvoluntary blood donors in Delhi, India. J. Health Popul. Nutr. 20: 348-351.

OLAMENDI, P., URIBE, Z.P., CALDERON, E., JUAREZ, F., URIBE, S. F. and HERNANDEZ, A.M. 1998. Low prevalence of hepatitis B markers among Mexican female sex worker. Sex Transm. Inf. 74: 448-450.

O'SHAUGHNESSY, D. 2000. Providing a safe and cost-effective blood transfusion service. Hospital Pharmacist. 7(5): 118-123.

POPOVSKY, M., CHAPLIN, H. and MOORE, S. 1995. Transfusion-related acute lung injury: a neglected, serious complication of hemotherapy" Transfusion. 32(6): 589-92.

SHILL, N. and BISWAS, J. 2006. A comparative study of donor screening tests by rapid chromatography and ELISA method for HBV, HCV and HIV. Bangladesh j medicine.17: 23-26.

SHIRIN, T., TAHMEED, A., ANWARUL, I., MUNIRUL, I. and NAZRUL, I. 2000. Prevalence and risk factors of hepatitis B virus, hepatitis $\mathrm{C}$ virus and HIV infection among drug addicts in Bangladesh. J. Health Popul. Nutr. 18(3): 145-150.

Simone, A., GLYNN, M.D., STEVEn, H.K., GEORGE, B.S., MICHAEL, P.B. and DAVID, J. 2000. For the Retrovirus Epidemiology Donor Study (REDS). JAMA. 284: 229-235.

SYED, A.M. 1996. Prevalence of HBV, HCV and HIV infections among family blood donors. Med. Res. Council Bull. 45: 26-28.

WHO Blood. 2003. The blood safety program in the Western Pacific Region. Bulletin WHO. 99-103.

WHO 2004. The blood safety programme in the Western Pacific Region was described in the work of Who. Bulletin of the World health organization. pp. 141-144.

ZHANG, J, ZOU, S. and GIULIVI, A. 2001. Epidemiology of hepatitis B in Canada. Can. J. Infect. Dis. 12:345-350.

(Manuscript received on 20 July, 2013; revised on 30 May, 2014) 